\title{
The impact of antiretroviral therapy on iron homeostasis and inflammation markers in HIV-infected patients with mild anemia
}

\author{
Eugenia Quiros-Roldan ${ }^{1}$, Francesco Castelli ${ }^{1}$, Paola Lanza ${ }^{1}$, Chiara Pezzoli ${ }^{2}$, Marika Vezzoli ${ }^{3}$, Inflammation in HIV \\ Study Group, Giorgio Biasiotto ${ }^{3,4 \dagger}$ and Isabella Zanella $a^{3,4^{*}+}$ (D)
}

\begin{abstract}
Background: Anemia is frequent during HIV infection and is predictive of mortality. Although CART has demonstrated to reduce its prevalence, several patients still experience unresolved anemia. We aimed to characterize iron homeostasis and inflammation in HIV-infected individuals with mild anemia in relation to CART.

Methods: In this retrospective cohort study, HIV-infected patients with mild anemia, CD4 ${ }^{+}$cells $>200 / \mathrm{mm}^{3}$ at baseline, maintaining virological response for 12 months after CART starting were selected within the Standardized Management of Antiretroviral Therapy Cohort (MASTER) cohort. Several inflammation and immune activation markers and iron homeostasis indexes were measured in stored samples, obtained at CART initiation (T0) and 12 months later (T1). Patients were grouped on the basis of hemoglobin values at T1: group A ( $>13 \mathrm{~g} / \mathrm{dl})$ and $\mathrm{B}(<13 \mathrm{~g} / \mathrm{dl})$. Wilcoxon rank sum test was used to compare biomarker values. Pearson correlation coefficients were calculated for all variables.

Results: $\mathrm{CART}$ improved $\mathrm{CD} 4^{+}$and $\mathrm{CD} 8^{+}$cell counts and their ratio, but this effect was significant only in group $\mathrm{A}$. Only these patients had mild iron deficiency at T0 and showed higher transferrin and lower percentage of transferrin saturation than patients of group B, but differences disappeared with CART. CART decreased inflammation in all patients, but group $B$ had higher levels of all markers than group A, reaching statistical significance only for IL-8 values at T1 (16 vs $2.9 \mathrm{pg} / \mathrm{ml} ; \mathrm{p}=0.017$ ). Hepcidin and IL-6 levels did not show significant differences between groups. Hemoglobin levels both at T0 and T1 did not correlate with any marker.

Conclusions: Baseline mild anemia in HIV-infected patients cannot always be resolved with durable efficient CART, possibly due to residual inflammation or immune activation rather than unbalanced iron homeostasis. Further research is needed on cytokine profiling to understand the mechanisms that induce anemia in HIV with suppressive CART.
\end{abstract}

Keywords: CART, HIV, Inflammation, Iron, Hepcidin, Anemia

\section{Background}

Chronic inflammation contributes to the development of anemia in both general population $[1,2]$ and human immunodeficiency virus (HIV)-infected people [3, 4]. Anemia is the most common haematological abnormality

\footnotetext{
${ }^{*}$ Correspondence: isabella.zanella@unibs.it

${ }^{\dagger}$ Giorgio Biasiotto and Isabella Zanella contributed equally to this work

${ }^{3}$ Department of Molecular and Translational Medicine, University

of Brescia, Brescia, Italy

Full list of author information is available at the end of the article
}

in HIV seropositive patients and is predictive of HIVassociated morbidity and mortality, independently of $\mathrm{CD} 4{ }^{+}$count [4-10].

Anemia in HIV infection is a complex mechanism. HIV itself produces chronic immune activation and inflammation and, under this inflammatory conditions, dietary iron is blocked from enterocyte release, whereas circulating iron is redistributed into cellular storage locations including macrophages. Additional HIV-associated consequences, including suppression of several hematopoietic cells [11] and opportunistic infections through 
inflammation further contribute to anemia during HIV infection. Although combination anti-retroviral therapy (cART) has demonstrated to reduce the prevalence of anemia in many HIV-infected patients, a considerable proportion of those patients experiences unresolved anemia or develop anemia after its initiation [12, 13]. Many studies have focused on the impact of cART on inflammation and immune activation markers [3, 12], but there are few prospective studies dealing with the association between anemia, iron metabolism and inflammation markers in HIV-infected individuals before and after cART [14].

The pathophysiology of anemia during infections is multifactorial, resulting from the effects of inflammatory cytokines, such as IL-6 and possibly other cytokines involved in host defense and leading to hepcidin-induced hypoferremia. The pro-inflammatory cytokine IL-6 is a dominant regulator of hepatic hepcidin production in bacterial infections and other inflammatory conditions, but IL-6 concentrations are often only mildly elevated in viral infections. Data on hepcidin levels in HIV infected patients are rarely reported [15-21].

Alterations of iron homeostasis are common in chronic inflammatory and infectious diseases [22]. In fact, prevalence of anemia among HIV-infected patients is high [3, 6] and it is frequently resolved after cART initiation [23, 24]. Sometimes, however, anemia can persist in HIVchronically-infected patients, even after HIV replication was suppressed with CART, and it has been associated with elevated levels of IL-6, CRP and D-dimer [3] and with monocyte activation [25]. This condition is considered as anemia of chronic inflammation.

This study was designed to characterize iron homeostasis and inflammation in relation to anemia at HIV diagnosis, and after the decline of virus titers in plasma due to cART introduction in a group of HIV-infected patients with mild anemia and $\mathrm{CD} 4^{+}$cells $>200 / \mathrm{mm}^{3}$.

\section{Methods \\ Patients}

We conducted a retrospective cohort study. Patients were recruited from the HIV-infected patients of the Standardized Management of Antiretroviral Therapy Cohort (MASTER cohort) followed in the University Department of Infectious and Tropical Diseases of the University of Brescia [26]. Anemia was defined based on WHO hemoglobin cutoffs [27]. We retrospectively selected all Caucasian HIV-infected male patients with the following characteristics: (i) hemoglobin $(\mathrm{Hb})$ value between 9.5 and $13 \mathrm{~g} / \mathrm{dl}$ and $\mathrm{CD} 4^{+}$cell count $>200 / \mathrm{mm}^{3}$ before cART initiation (T0); (ii) plasma HIV RNA < 37 copies/ml after 6 months of first cART; (iii) maintained cART response (plasma HIV RNA < 37 copies/ml at 6 and 12 months of stable cART) ( $11=12$ months); (iv) available plasma samples either at $\mathrm{T} 0$ and $\mathrm{T} 1$, stored at $-80{ }^{\circ} \mathrm{C}$. Patients were classified into 2 groups: group $\mathrm{A}$, with $\mathrm{Hb}<13 \mathrm{~g} / \mathrm{dl}$ at $\mathrm{T} 0$ and $\mathrm{Hb}>13 \mathrm{~g} / \mathrm{dl}$ at $\mathrm{T} 1$ and group $\mathrm{B}$, with $\mathrm{Hb}<13 \mathrm{~g} /$ $\mathrm{dl}$ both at T0 and T1. Exclusion criteria were: (i) severe anemia $(\mathrm{Hb}<8 \mathrm{~g} / \mathrm{dl})$, (ii) acute HIV-infection, (iii) severe concomitant diseases (opportunistic infections, cancer) at T0 or during the study period, congenital disorders of $\mathrm{Hb}$ synthesis, (iv) also female gender was a criterion for exclusion to reduce the confounding of iron loss.

\section{Assessment of inflammatory and iron metabolism markers} Plasma samples at T0 and T1 were tested for levels of predefined inflammatory and iron homeostasis markers. Serum $C$ reactive protein (CRP), iron and transferrin (TF) were quantified using the Dimension Vista 5 Siemens automated analyzer, using commercially available reagents (Siemens Healthcare $\mathrm{GmbH}$, Erlangen, Germany). The percentage of transferrin saturation (\%TS) was calculated on the basis of iron and TF values. Serum ferritin levels were measured using the Abbott Architect automated analyzer with the Abbott Architect Ferritin Assay (Abbott Laboratories, Chicago, IL, US). Hb levels were determined using the Beckman Coulter Unicell DxH800analyzer (Beckman Coulter, Brea, CA, US). IL-2, IL-3, IL-4, IL-5, IL-7, IL-8, IL-10, IL-18, interferon- $\gamma$ (IFN- $\gamma$ ), tumor necrosis factor- $\alpha$ (TNF- $\alpha$ ), tumor necrosis factor- $\gamma$ (TNF- $\gamma$ ), Macrophage inflammatory protein$1-\alpha$ (MIP-1- $\alpha$ ), macrophage inflammatory protein-1- $\beta$ (MIP-1- $\beta$ ), monocyte chemotactic protein 1 (MCP-1) and granulocyte-macrophage colony-stimulating factor (GM-CSF) serum levels were measured using the Myriad RBM Cytokine MAP A panel (Myriad RBM, Austin TX, US). Commercial ELISA kits were used to quantify serum levels of IL-6, IL-22 (Cloud-Clone Corporation, Houston, TX, USA) and hepcidin (DRG Diagnostic, Marburg, Germany), according to the manufacturer's protocols.

\section{Statistical analysis}

Student's $t$ test (for age) and $\chi^{2}$ test (for HCV coinfection, tobacco and intravenous drug use) were used to compare patients of group A and B for demographic and epidemiological characteristics. Quantitative variables were compared at baseline (T0) and 12 months later (T1) using Wilcoxon rank sum tests for paired samples in all samples $(n=18)$, group $A(n=10)$ and group $B(n=8)$. The same variables were analyzed comparing group $A$ vs group $\mathrm{B}$, both at $\mathrm{T} 0$ and $\mathrm{T} 1$, using Wilcoxon rank sum tests for independent samples. $p<0.05$ was considered to be statistically significant. Pearson correlation coefficients were computed to determine possible associations between biomarkers, resulting in a symmetric correlation matrix (Additional file 1) (highlighted in bold the 
coefficients major of 0.7 in absolute value, when $p$ values are $<0.05$ ). In heatmap graphical representation, values contained in a datamatrix, previously standardized with mean 0 and standard deviation 1 , were represented with colors. In detail, low (negative), mean (near to 0), and high (positive) values were represented with blue, yellow and red, respectively. Heatmaps place similar values near each other according to the clustering algorithm used in the analysis which is based on the Euclidean distance. Hence, we obtained two dendrograms which were added to the heatmap on $x$-and $y$-axis, respectively.

\section{Ethics statement}

The study was conducted in accordance with the Declaration of Helsinki and the principles of Good Clinical Practice. All patients provided written informed consent to include their clinical and biological data in the MASTER database [22]. All patients signed the informed consent for archiving a plasma sample at baseline and every 6 months for scientific purposes. The study was approved by the Ethical Committee of the Civic Hospital of Brescia (Coordinating Centre) and of all the participant Centers [26].

\section{Results}

The studied population consisted of 18 HIV-1-infected treatment-naive patients with mild anemia ( $\mathrm{Hb}$ value between 9.5 and $13 \mathrm{~g} / \mathrm{dl}$ ) at time of initiating cART (T0). After cART, all patients had plasma HIV-1 RNA levels consistently < 37 copies $/ \mathrm{ml}$, as measured by commercial assays at 6,9 and 12 months of treatment. Ten patients increased $\mathrm{Hb}$ values above $13 \mathrm{~g} / \mathrm{dl}$ at $\mathrm{T} 1$ and then they were retrospectively included in group $\mathrm{A}$ (median $\mathrm{Hb}$ values: $\mathrm{T} 0=12.70 \mathrm{~g} / \mathrm{dl} ; \mathrm{T} 1=14.25 \mathrm{~g} / \mathrm{dl} ; \mathrm{p}=0.0020$ ), while 8 patients remained anemic at $\mathrm{T} 1$ and were retrospectively included in group B (median Hb values: T0 $=11.85 \mathrm{~g}$ / $\mathrm{dl} ; \mathrm{T} 1=11.95 \mathrm{~g} / \mathrm{dl} ; \mathrm{p}=0.3828$ ). The characteristics of the population are shown in Table 1. Among patients of group $\mathrm{A}$, none used intravenous drugs or had hepatitis $\mathrm{C}$ virus $(\mathrm{HCV})$ chronic infection and only $30 \%$ were habitual smokers. Among patients of group B, HCV chronic infection was present in $62.5 \%$ (5 out 8 ) of patients, but any HCV coinfected patient was under HCV treatment, $75 \%$ ( 6 out 8 ) had acquired HIV-infection by intravenous drug use and $100 \%$ were smokers.

As expected, cART improved $\mathrm{CD}^{+}{ }^{+}$cell count, and $\mathrm{CD} 4^{+} / \mathrm{CD}^{+}$ratio (T0 vs $\mathrm{T} 1$ median values). This effect was statistically significant for patients from group A, but not for those from group B (Table 2).

\section{Iron metabolism}

Patients of group A, who resolved anemia with cART, had mild iron deficiency at T0, but a trend to the increase of serum iron levels with anti-retroviral therapy was observed (from $54 \mathrm{mg} / \mathrm{dl}$ at $\mathrm{T} 0$ up to $71 \mathrm{mg} / \mathrm{dl}$ at T1). Conversely, in patients of group B, plasma iron levels were within the reference values $(>60 \mathrm{mg} / \mathrm{dl}$ for adult male), despite of anemia and significantly higher than in patients of group A at T0 $(85.5 \mathrm{mg} / \mathrm{dl}$ vs $54 \mathrm{mg} / \mathrm{dl}$; $\mathrm{p}=0.0455)$ and iron values did not significantly changed with cART ( $\mathrm{T} 0=85.5 \mathrm{mg} \mathrm{dl}$ and at $\mathrm{T} 1=70.5 \mathrm{mg} / \mathrm{dl}$, $\mathrm{p}=0.3828$ ). Further, while TF levels did not significantly change in both groups with cART, patients of group A had higher TF values than patients of group B at both times, although the difference was not statistically significant $(203 \mathrm{mg} / \mathrm{dl}$ vs $184.5 \mathrm{mg} / \mathrm{dl}$ at $\mathrm{T} 0 ; \mathrm{p}=0.3154$; and $215.5 \mathrm{mg} / \mathrm{dl}$ vs $184.5 \mathrm{mg} / \mathrm{dl}$ at $\mathrm{T} 1 ; \mathrm{p}=0.0619)$. The \%TS was significantly lower in patients of group $\mathrm{A}$ than in patients of group B at T0 (21.41\% vs $34.28 \%$; $\mathrm{p}=0.0085)$, but the difference disappeared with cART $(29.83 \%$ vs 30.02\%; $\mathrm{p}=0.6334$ ) (Table 2).

\section{Inflammation markers}

In general, cART decreased values of several inflammatory markers in all patients. But, while in patients of group A, the decrease was significant only for ferritin $(192.5 \mathrm{ng} / \mathrm{ml}$ vs $80 \mathrm{ng} / \mathrm{ml} ; \mathrm{p}=0.0488)$, in patients of group B it was significant for IL-18 $(428 \mathrm{pg} / \mathrm{ml}$ vs $348 \mathrm{pg} / \mathrm{ml} ; \mathrm{p}=0.0391)$ and MCP- $1(166 \mathrm{pg} / \mathrm{ml}$ vs $131 \mathrm{pg} /$ $\mathrm{ml} ; \mathrm{p}=0.0360)$. Further, we found that all inflammatory markers were always higher in patients of group $B$ than in patients of group A, although reaching statistical significance only for IL-8 values at T1 (16 vs $2.9 \mathrm{pg} / \mathrm{ml}$; $\mathrm{p}=0.017$ ) (Table 2).

Table 1 Demografic and epidemiological characteristics of patients

\begin{tabular}{lllll}
\hline & Total $(\mathbf{n}=\mathbf{1 8})$ & Group A $(\mathbf{n}=\mathbf{1 0})$ & Group B $(\mathbf{n}=\mathbf{8})$ & $\boldsymbol{p}$ value \\
\hline Age (years) (mean \pm SD) & $42.8 \pm 8.6$ & $45.6 \pm 9.6$ & $39.3 \pm 6.0$ & 0.1221 \\
HCV infected (n\%) & $5(27.8 \%)$ & 0 & $5(62.5 \%)$ & 0.0033 \\
Smokers (n\%) & $11(61.1 \%)$ & $3(30 \%)$ & $8(100 \%)$ & 0.0025 \\
Intravenous drug users & $6(33.3 \%)$ & 0 & $6(75 \%)$ & 0.0019 \\
\hline
\end{tabular}

Student's $t$ test was used to compare age and $x^{2}$ test to compare HCV coinfection, tobacco and intravenous drug use 


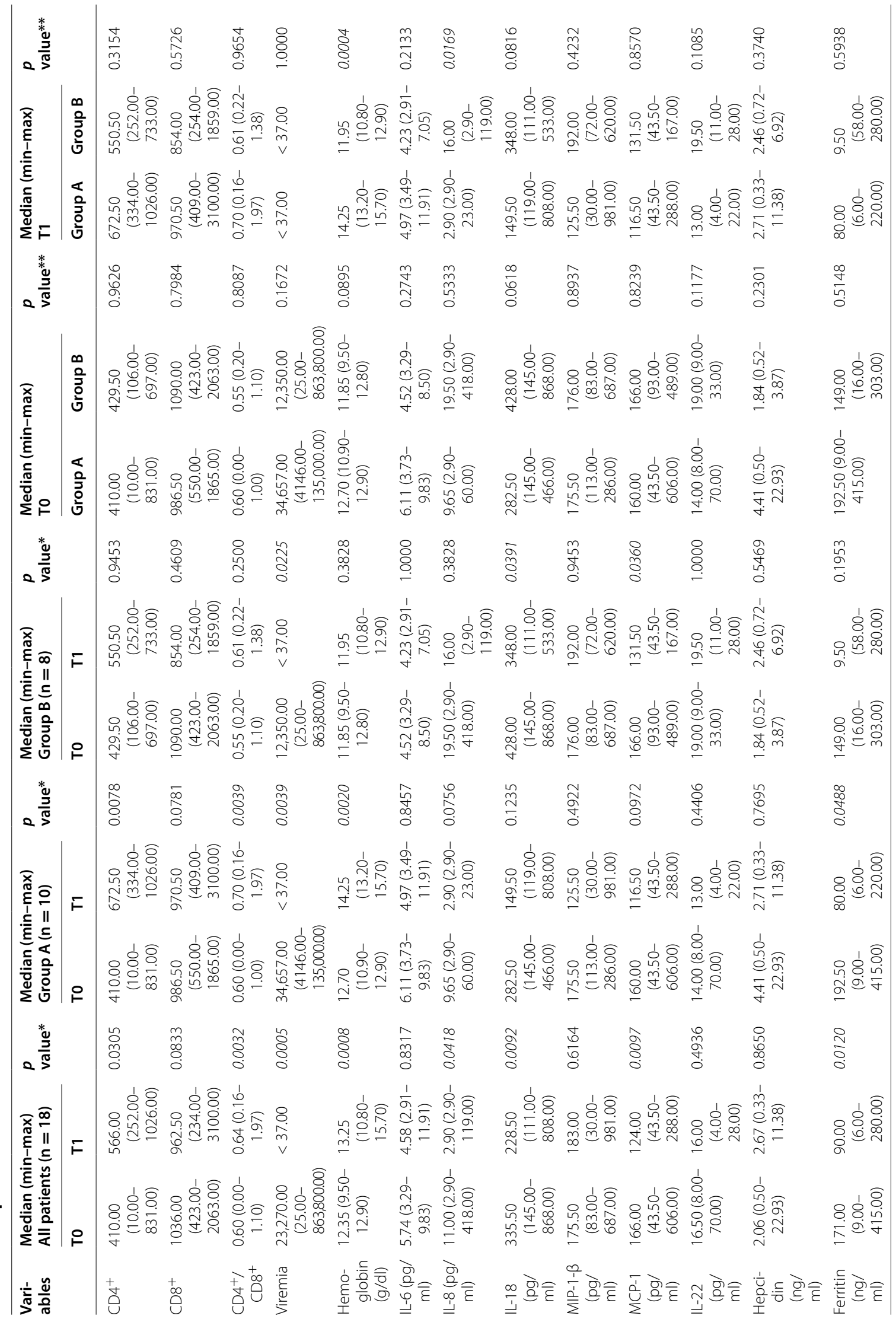




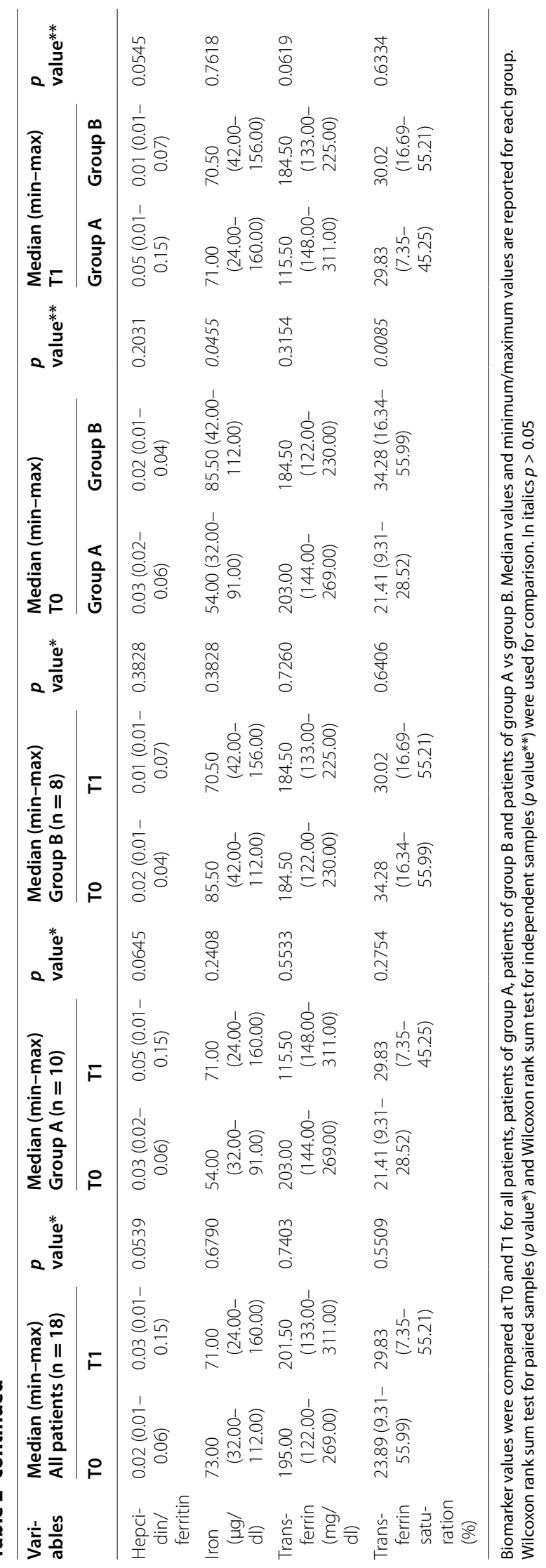


Only in patients of group B, we observed that cART increased MIP-1- $\beta$ and hepcidin values, although the increase did not reach the statistical significance $(176 \mathrm{pg} /$ $\mathrm{ml}$ vs $192 \mathrm{pg} / \mathrm{ml} ; \mathrm{p}=0.9453$; and 1.84 vs $2.46 \mathrm{ng} / \mathrm{ml}$; $\mathrm{p}=0.5469$, respectively). Hepcidin and IL-6 levels did not show significant differences between groups, but a trend toward higher levels in group A vs group B were observed (hepcidin at T0: $4.41 \mathrm{ng} / \mathrm{ml}$ vs $1.84 \mathrm{ng} /$ $\mathrm{ml} ; \mathrm{p}=0.2301$; hepcidin at $\mathrm{T} 1: 2.71 \mathrm{ng} / \mathrm{ml}$ vs $2.46 \mathrm{ng} /$ $\mathrm{ml} ; \mathrm{p}=0.3740$; IL-6 at T0: $6.11 \mathrm{pg} / \mathrm{ml}$ vs $4.52 \mathrm{pg} /$ $\mathrm{ml} ; \mathrm{p}=0.2743$; IL-6 at T1: $4.97 \mathrm{pg} / \mathrm{ml}$ vs $4.23 \mathrm{pg} / \mathrm{ml}$; $\mathrm{p}=0.2133)$. Interestingly, the ratio hepcidin/ferritin increased with cART in patients of group A ( 0.03 vs 0.05 ; $\mathrm{p}=0.0645)$, but decreased in patients of group $\mathrm{B}(0.02 \mathrm{vs}$ $0.01 ; \mathrm{p}=0.3828$ ) (Table 2).

Serum levels of some markers were below the detection limit of the assays (CRP, IL-2, IL-3, IL-4, IL-5, IL-7, GM-CSF, TNF- $\beta$ and IFN- $\gamma$ ) in most patients and were not included in the study, while for most samples IL-10, TNF- $\alpha$ and MIP-1- $\alpha$ were detectable and interestingly decreased below the detection limit at $\mathrm{T} 1$ only in patients from group A (Fig. 1).
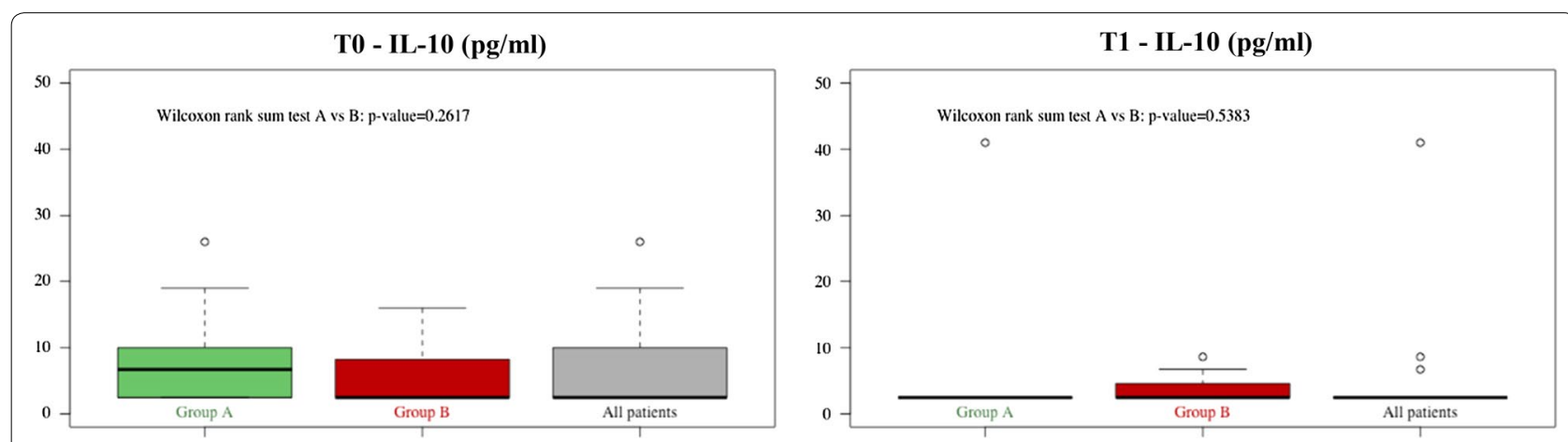

T0 - TNF- $\alpha(\mathrm{pg} / \mathrm{ml})$

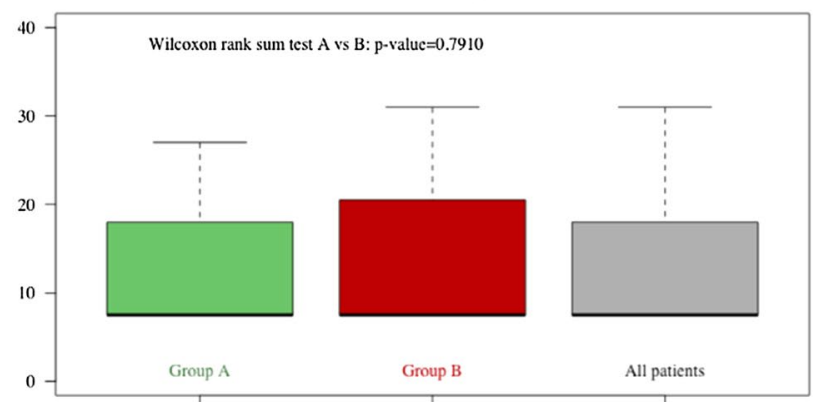

T1 - TNF- $\alpha \mathrm{pg} / \mathrm{ml}$

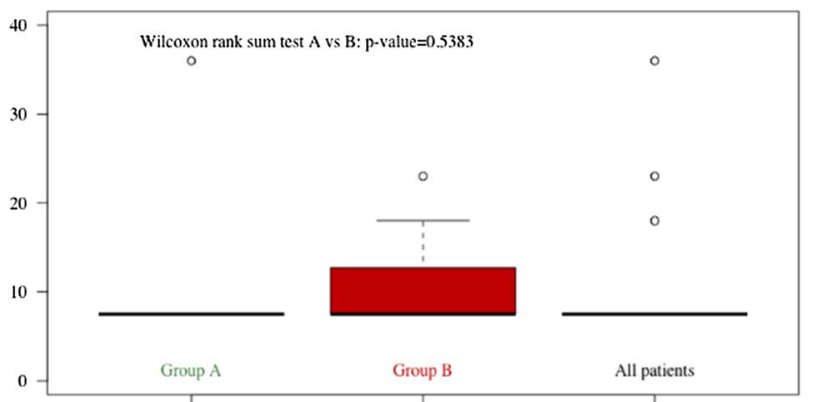

T0 - hepcidin (ng/ml)

T1 - hepcidin (ng/ml)
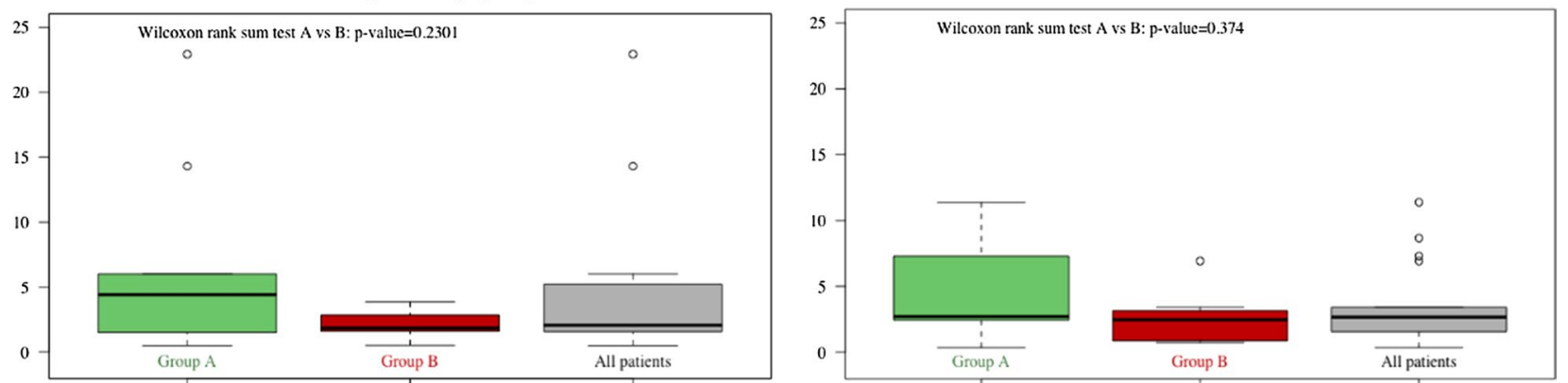

Fig. 1 Biomarker levels in HIV-infected patients. Serum levels of IL-10, tumor necrosis factor a (TNF-a) and hepcidin in HIV-infected patients at baseline (T0) and after 12 months (T1) of combination anti-retroviral therapy (CART) in group A, group B and all patients. Wilcoxon rank sum test for independent samples was used to compare median values of patients of group A vs patients of group B. Outliers were identified by means of circles. $p$ values are also reported 


\section{Correlation matrix and heatmaps representation}

We did not found linear relationship between $\mathrm{Hb}$ or iron levels when all 18 patients were considered together with hepcidin, any marker of inflammation, $\mathrm{CD} 4^{+}, \mathrm{CD} 8^{+}$cell count or $\mathrm{CD}^{+} / \mathrm{CD}^{+}$ratio (Additional file 1). We also performed the heatmap analysis to identify possible clusters or pathways among variables (Fig. 2). Interestingly, only in group B, iron was clustered among inflammatory markers both at $\mathrm{T} 0$ and $\mathrm{T} 1$, but not with $\mathrm{Hb}, \mathrm{TF}$, hepcidin and IL-6.

\section{Discussion}

Here, we describe that baseline mild anemia in HIVinfected patients cannot always be resolved with durable efficient cART. In general, cART decreased values of inflammatory markers and ameliorated iron metabolism in all patients. But HIV-infected patients with anemia that is resolved with cART had lower levels of IL-8, IL-18, IL-22, MIP-1- $\beta$ and MCP-1 and higher IL-6 and hepcidin levels than patients with persistent anemia, either at T0 and T1. On the other hand, HIV-infected
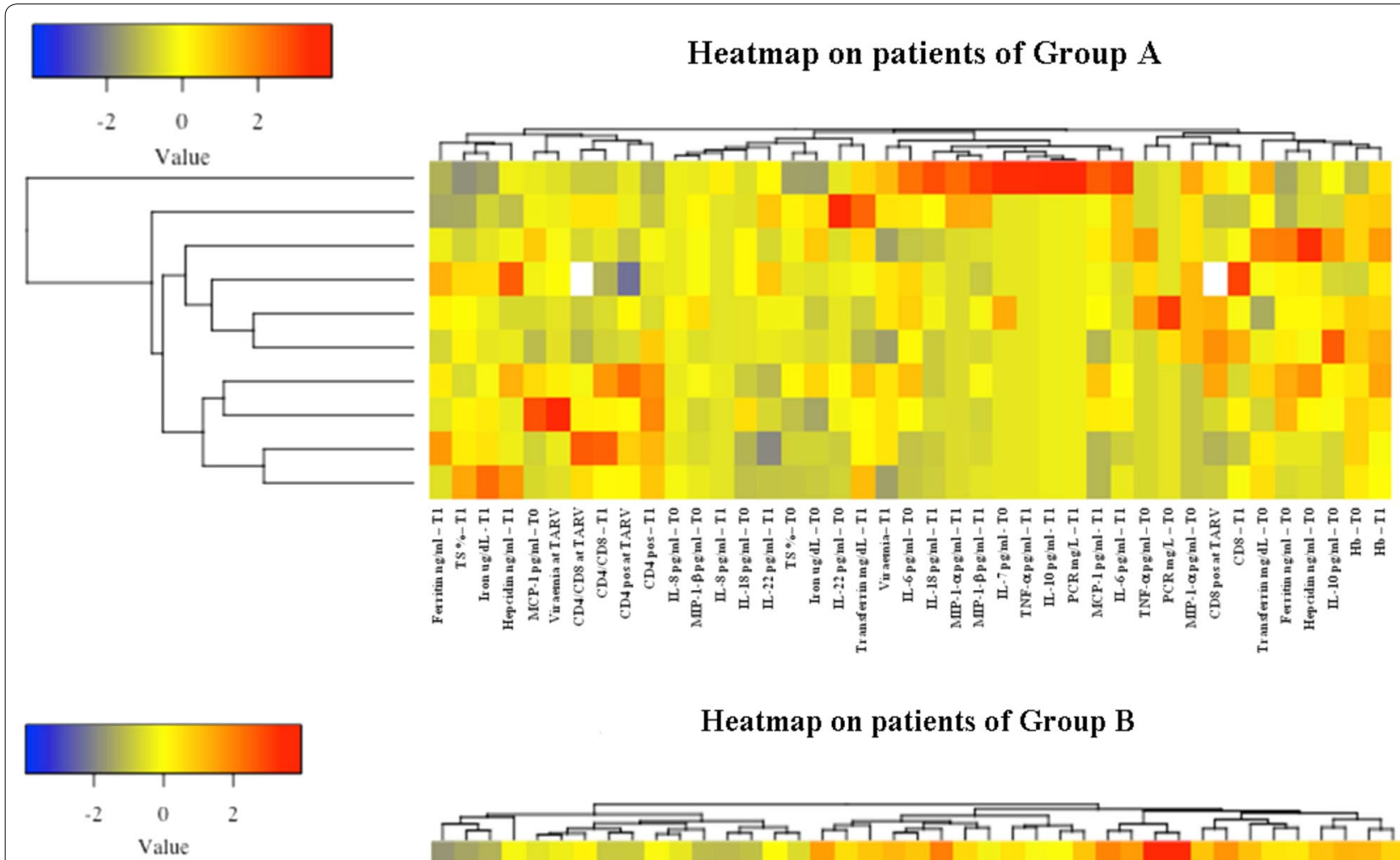

Heatmap on patients of Group B
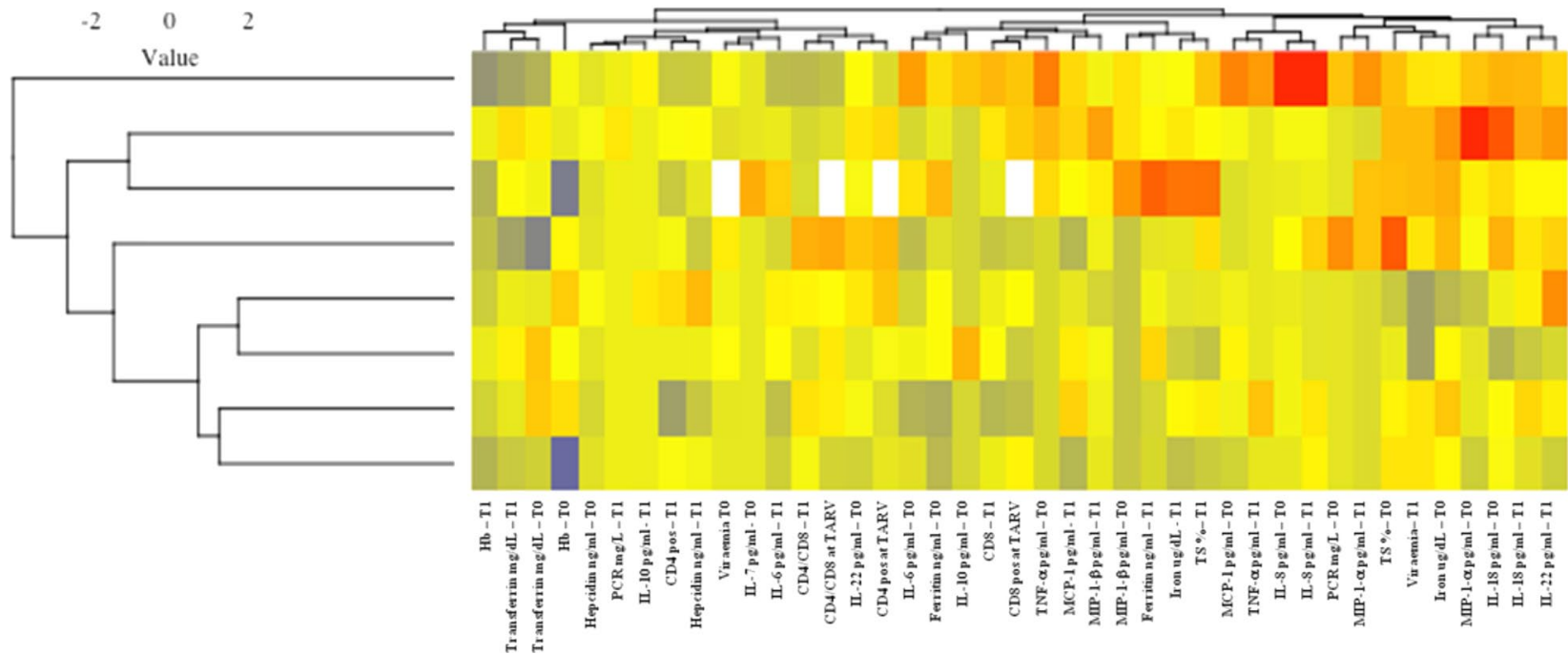

Fig. 2 Heatmap analysis. Heatmap analysis on biomarker levels relative to patients in group A and in group B 
patients with anemia that is not resolved with cART are frequently coinfected with $\mathrm{HCV}(62 \%)$, and at baseline they have higher values of iron, \%TS and IL-18 and a trend toward lower levels of hepcidin and IL-6, compared to those patients in whom anemia was resolved by cART. Furthermore, patients with persistent anemia had minor immune recovery.

Several studies in HIV-infected patients have found an inverse association between hepcidin and absolute CD4 ${ }^{+}$ cell count $[17,21]$, suggesting that elevated hepcidin may be ascribed to advanced disease stage and elevated levels of inflammation. Most recently, Rosado-Sanchez et al. [28] observed that high levels of IL-6, CRP, high CD4 ${ }^{+}$ cell turnover and regulatory $\mathrm{T}$ cell (Treg) frequency are already present prior to initiation of cART in HIVinfected patients with poorer $\mathrm{CD}^{+}$cell recovery, suggesting a role of inflammation on $\mathrm{CD} 4^{+}$cell homeostasis. In HIV-infected patients the chronic exposure to other antigens or pathogens, like cytomegalovirus (CMV) or $\mathrm{HCV}$, may also contribute to persistent inflammation or immune activation [29-31] and clinical events [32, 33]. In cART-treated HIV-infection with minimal CD4 ${ }^{+}$ cell defects, HCV seems not to be associated with cellular immune activation, but it may rather contribute to immune exhaustion [30]. In our study that includes HIVinfected patients from an Italian cohort with mild anemia and median $\mathrm{CD}^{+}$cells $>400 / \mathrm{mm}^{3}$ at baseline, cART significantly increased $\mathrm{CD} 4^{+}$cell count in patients of group A (none HIV/HCV infected), but not in group B (62\% of them was HIV/HCV coinfected).

cART initiation consistently leads to decrease in most systemic inflammatory markers, T cell indices and monocyte activation, albeit rarely to levels comparable to those of HIV-uninfected individuals [34]. This chronic state of inflammation/immune activation, that it is established during HIV-infection as a result of the complex interactions between viral and host factors, may be associated to clinical consequences despite of efficient cART. Increased values of IL-18 have been associated with clinical cART failure in HIV-infected patients [35] and high level of IL-8 has been associated with lower number of $\mathrm{CD} 4^{+}$ cell count and HIV disease progression in children [36]. Patients of group B in our study, who did not recover from anemia, had indeed higher levels of IL-8 and IL-18.

Many potential mechanisms for this chronic inflammatory state have been proposed: HIV itself, translocated microbial products, other chronic concomitant pathogens, including CMV and HCV, and lipids [37, 38]. Despite of cART success, HIV/HCV coinfected patients have poorer prognosis and more rapid progression of liver disease, probably due to the excessive inflammation/ immune activation in $\mathrm{HIV} / \mathrm{HCV}$ coinfection, compared to either HIV or HCV mono-infection $[39,40]$.
Interactions between $\mathrm{HIV}$ and $\mathrm{HCV}$ in respect to inflammation and iron metabolism are complex and poorly known. Distinct patterns of iron homeostasis occur during different viral infections. Acute HIV infection causes a decrease of serum iron that is accompanied by increase in hepcidin, CRP, IL-10, IL-18 and TNF- $\alpha$. Levels remained elevated in cART treated patients, in spite of undetectable HIV replication and $\mathrm{Hb}$ normalization. Interestingly, hepcidin up-regulation or hypoferremia were not evidenced during acute $\mathrm{HCV}$ or $\mathrm{HBV}$ infection [19]. In contrast, a recent study in chronically $\mathrm{HCV}$-infected patients has showed that liver disease activity has a negative impact on erythropoiesis with compensatory higher but blunted EPO responses [41].

Data are emerging about differences between HIV monoinfected and HIV/HCV coinfected patients in levels of markers of inflammation and iron metabolism dysregulation. In vitro co-stimulation of HepG2 cells with HCV-E2 and HIV-gp120 proteins induces a potent proinflammatory response with the production of IL-8 [42] and it is suggested that in vivo IL-8 could be responsible for the local inflammatory changes that induce fibrosis in $\mathrm{HCV}$-infected patients and the severe liver damage observed in HCV/HIV co-infected patients [43]. Higher plasma levels of IL-6, IL-8, IL-18 and MIP-1- $\beta$ have been recently observed in HIV/HCV coinfected patients than in both monoinfections. It has been hypothesized that high levels of some of these cytokines could be responsible for the increased incidence and progression of inflammatory illness in $\mathrm{HIV} / \mathrm{HCV}$ chronically coinfected patients, even in patients on cART with undetectable HIV RNA [30, 44]. Here, we observed that cART decreased IL-8, IL-18 and MCP-1 in all patients, however their levels remained higher in group $\mathrm{B}$ than in group A. cART has been described to induce slow fibrosis progression in $\mathrm{HIV} / \mathrm{HCV}$-coinfected patients with successful HIV suppression, but progression remains accelerated compared with $\mathrm{HCV}$-monoinfected patients [45]. Indeed, recent studies have shown that hepcidin levels is reduced in both liver and serum of patients with $\mathrm{HCV}$ infection, which may contribute to pathological liver iron storage and elevated serum ferritin and iron levels [46-48].

We found that IL-8 level was higher in group B (that included most of patients with chronic HCV infection) than in group A and, although cART decreased its level in both groups, it remained significantly higher in group B. These patients were anemic with normal values of serum iron and \%TS, significantly higher than those of patients of group A at T0, and, despite the control of HIV replication with cART for more than 6 months.

Our study has some limitations. First, the study was performed in a limited number of patients. Second, we do not know if there were differences in time of 
infection between the two groups, despite the fact that both groups showed similar time from diagnosis and the mean of $\mathrm{CD}^{+}{ }^{+}$cells between groups was similar. Third, the present study was not designed to analyze differences in inflammatory cytokine or iron marker levels between HIV/HCV and HIV monoinfected patients, but, casually, most patients of group B were $\mathrm{HIV} / \mathrm{HCV}$ infected $[39,49]$. The longitudinal design of this study, in contrast with other studies comparing several groups in a cross-sectional way, confers it an important strength. The participants in this cohort had sustained virologic suppression, below the limits of detection of commercial assays, mitigating the potential effects of virologic failure or transient viremia on measures of anemia or inflammation, that might be observed in less-adherent individuals. Another strength of the present study is the high number of inflammatory markers tested.

\section{Conclusions}

Additional inflammation other than HIV-mediated can be responsible for the persistent mild chronic anemia and for the slower $\mathrm{CD}_{4}^{+}$and $\mathrm{CD}_{4}^{+} / \mathrm{CD}^{+}$increase in patients with sustained plasmatic HIV suppression by cART. Understanding the mechanisms that mediate the inflammation/immune activation in HIV with suppressive cART is a challenging issue. Profiling the cytokines will plausibly enable identification of factors that could complement the information from viral load and $\mathrm{CD} 4^{+}$ cell counts in the management of the disease and therapeutic interventions.

\section{Additional file}

Additional file 1. Pearson correlation analysis. Pearson correlation analysis between variables considered in this study ( $\mathrm{Hb}$, HIV-related factors, markers of iron homeostasis, of immune activation and inflammation). In bold Pearson correlation coefficients with rho $>|0.7|$ and $p$ values $<0.05$ are shown.

\section{Abbreviations}

CART: combination anti-retroviral therapy; CRP: C reactive protein; CMV: cytomegalovirus; GM-CSF: granulocyte-macrophage colony-stimulating factor; $\mathrm{Hb}$ : hemoglobin; HCV: hepatitis C virus; HIV: human immunodeficiency virus; IL-2: interleukine-2; IL-3: interleukine-3; IL-4; interleukine-4; IL-5: interleukine-5; IL-6: interleukine-6; IL-7: interleukine-7; IL-8: interleukine-8; IL-10: interleukine-10; IL-18: interleukine 18; IL-22: interleukine-22; IFN- $-\gamma$ interferon- $\gamma$; MCP-1: monocyte chemotactic protein 1; MIP-1-a: macrophage inflammatory protein-1- $\alpha$; MIP-1- $\beta$ : macrophage inflammatory protein-1- $\beta$; $\%$ TS: percentage of transferrin saturation; TF: transferrin; Treg: regulatory T cell; TNF-a: tumor necrosis factor- $\alpha$; TNF- $\beta$ : tumor necrosis factor- $\beta$.
}

\section{Authors' contributions}

QRE, ZI, BG and CF conceived the study. QRE, LP and CP made substantial contributions to the acquisition of clinical data. ZI and BG performed laboratory tests. VM performed statistical analysis. EQR, ZI and BG wrote the first version of the manuscript. All authors revised critically for important intellectual content. All authors read and approved the final manuscript.

\author{
Author details \\ ${ }^{1}$ University Department of Infectious and Tropical Diseases, University \\ of Brescia and Spedali Civili General Hospital, Brescia, Italy. ${ }^{2}$ University Depart- \\ ment of Infectious and Tropical Diseases, Spedali Civili General Hospital, \\ Brescia, Italy. ${ }^{3}$ Department of Molecular and Translational Medicine, University \\ of Brescia, Brescia, Italy. ${ }^{4}$ Laboratory of Clinical Chemistry, Department \\ of Diagnostics, Civic Hospital of Brescia, Brescia, Italy.
}

\section{Acknowledgements}

We thank all patients, doctors, nurses and the dedicated staff of the local center: University Department of Infectious Diseases of Spedali Civili Hospital, University of Brescia, Brescia. We are also grateful to Eng. Andrea Zanella for helpful language editing.

We wish also to thank the "Inflammation in HIV Study Group": Dr. Alessandro Montanelli, Laboratory of Clinical Chemistry, Department of Diagnostics, Civic Hospital of Brescia, Italy; Dr. Giuseppina Ruggeri, Laboratory of Clinical Chemistry, Department of Diagnostics, Civic Hospital of Brescia, Italy; Prof. Eugenio Monti, Department of Molecular and Translational Medicine, University of Brescia, Italy; Dr. Andrea Bonito, University Department of Infectious and Tropical Diseases, University of Brescia and Spedali Civili General Hospital, Brescia, Italy; Dr. Alice Ferraresi, University Department of Infectious and Tropical Diseases, University of Brescia and Spedali Civili General Hospital, Brescia, Italy; Dr. Emanuele Focà, University Department of Infectious and Tropical Diseases, University of Brescia and Spedali Civili General Hospital, Brescia, Italy; Dr. Ilaria Izzo, University Department of Infectious and Tropical Diseases, Spedali Civili General Hospital, Brescia, Italy.

\section{Competing interests}

The authors declare that they have no competing interests.

\section{Availability of data and materials}

For ethical and legal restriction we cannot upload a minimal dataset. The data are available upon request, the interested researchers could contact directly Dr. Eugenia Quiros-Roldan (eugeniaquiros@yahoo.it).

\section{Consent for publication}

Not applicable.

\section{Ethics approval and consent to participate}

The study was carried out in accordance with the Declaration of Helsinki and the principles of Good Clinical Practice. All patients provided written informed consent to include their clinical and biological data in the MASTER database [ref. 22]. The study was approved by the Ethical Committee of the Civic Hospital of Brescia (Coordinating Centre) [ref. 22].

\section{Funding}

MASTER Cohort was funded by M.I.S.I. foundation (http://www.fondazionemisi.it/). This work was also supported by the University of Brescia (Fondi ex $60 \%$ to I.Z. and G.B.) and by an unconditional grant by ViiV Health Care. These funding sources had no role in the design of this study, analyses, interpretation of the data, or decision to submit results.

\section{Publisher's Note}

Springer Nature remains neutral with regard to jurisdictional claims in published maps and institutional affiliations.

Received: 14 July 2017 Accepted: 6 December 2017

Published online: 19 December 2017

\section{References}

1. Raj DS. Role of interleukin-6 in the anemia of chronic disease. Semin Arthritis Rheum. 2009;38(Suppl 5):382-8.

2. Weiss G, Goodnough LT. Anemia of chronic disease. N Engl J Med. 2005;352:1011-23.

3. Borges ÁH, Weitz JI, Collins G, Baker JV, Lévy Y, Davey RT Jr, et al. Markers of inflammation and activation of coagulation are associated 
with anemia in antiretroviral-treated HIV disease. AIDS. 2014;28(Suppl 12):1791-6.

4. Shivakoti R, Yang WT, Gupte N, Berendes S, Rosa AL, Cardoso SW, et al. Concurrent anemia and elevated C-reactive protein predicts HIV clinical treatment failure, including tuberculosis, after antiretroviral therapy initiation. Clin Infect Dis. 2015;61(Suppl 1):102-10.

5. Harris RJ, Sterne JA, Abgrall S, Dabis F, Reiss P, Saag M, et al. Prognostic importance of anemia in HIV type-1-infected patients starting antiretroviral therapy: collaborative analysis of prospective cohort studies. Antivir Ther. 2008;13(Suppl 8):959-67.

6. Belperio PS, Rhew DC. Prevalence and outcomes of anemia in individuals with human immunodeficiency virus: a systematic review of the literature. Am J Med. 2004;116(Suppl 7A):27S-43S.

7. McDermid JM, Jaye A, Schim van der Loeff MF, Todd J, Bates C, Austin $S$, et al. Elevated iron status strongly predicts mortality in West African adults with HIV infection. J Acquir Immune Defic Syndr. 2007;46(Suppl 4):498-507.

8. McDermid JM, van der Loeff MF, Jaye A, Henning BJ, Bates C, Todd J, et al. Mortality in HIV infection is independently predicted by host iron status and SLC11A1 and HP genotypes, with new evidence of a gene-nutrient interaction. Am J Clin Nutr. 2009;90(Suppl 1):225-33.

9. McDermid JM, Henning BJ, van der Sande M, Hill AVS, Whittle HC, Jaye $A$, et al. Host iron redistribution as a risk factor for incident tuberculosis in HIV infection: an 11-year retrospective cohort study. BMC Infect Dis. 2013;13:48

10. Rawat R, Humphrey JH, Ntozini R, Mutasa K, lliff PJ, Stoltzfus RJ. Elevated iron stores are associated with HIV disease severity and mortality among postpartum women in Zimbabwe. Public Health Nutr. 2009;12(Suppl 9):1321-9.

11. Huang SS, Barbour JD, Deeks SG, Huang JS, Grant RM, Ng VL, et al. Reversal of human immunodeficiency virus type 1-associated hematosuppression by effective antiretroviral therapy. Clin Infect Dis. 2000;30(Suppl 3):504-10.

12. Sarcletti M, Quirchmair G, Weiss G, Fuchs D, Zangerle R. Increase of haemoglobin levels by anti-retroviral therapy is associated with a decrease in immune activation. Eur J Haematol. 2003;70(Suppl 1):17-25.

13. Berhane K, Karim R, Cohen MH, Masri-Lavine L, Young M, Anastos K, et al. Impact of highly active antiretroviral therapy on anemia and relationship between anemia and survival in a large cohort of HIV-infected women: Women's Interagency HIV Study. J Acquir Immune Defic Syndr. 2004;37(Suppl 2):1245-52.

14. Hattab S, Guihot A, Guiguet M, Fourati S, Carcelain G, Caby F, et al. Comparative impact of antiretroviral drugs on markers of inflammation and immune activation during the first two years of effective therapy for HIV-1 infection: an observational study. BMC Infect Dis. 2014;14:122.

15. Kerkhoff AD, Meintjes G, Opie J, Vogt M, Jhilmeet N, Wood R, Lawn SD Anaemia in patients with HIV-associated TB: relative contributions of anaemia of chronic disease and iron deficiency. Int J Tuberc Lung Dis. 2016:20:193-201.

16. Kerkhoff AD, Meintjes G, Burton R, Vogt M, Wood R, Lawn SD. Relationship between blood concentrations of hepcidin and anemia severity, mycobacterial burden, and mortality among patients with HIV-associated tuberculosis. J Infect Dis. 2016;213:61-70

17. Minchella PA, Armitage AE, Darboe B, Jallow MW, Drakesmith H, Jaye A, et al. Elevated hepcidin is part of a complex relation that links mortality with iron homeostasis and anemia in men and women with HIV infection. J Nutr. 2015;145(Suppl 6):1194-201.

18. Minchella PA, Armitage AE, Darboe B, Jallow MW, Drakesmith H, Jaye $A$, et al. Elevated hepcidin at HIV diagnosis is associated with incident tuberculosis in a retrospective cohort study. Int J Tuberc Lung Dis. 2014;18:1337-9.

19. Armitage AE, Stacey AR, Giannoulatou E, Marshall E, Sturges P, Chatha $\mathrm{K}$, et al. Distinct patterns of hepcidin and iron regulation during HIV-1, HBV, and HCV infections. Proc Natl Acad Sci USA. 2014;111(Suppl 33):12187-92

20. Malvoisin E, Makhloufi D, Livrozet JM. Serum hepcidin levels in women infected with HIV-1 under antiviral therapy. J Med Virol. 2014;86:1656-60.

21. Wisaksana R, de Mast Q, Alisjahbana B, Jusuf H, Sudjana P, Indrati AR, et al. Inverse relationship of serum hepcidin levels with CD4 cell counts in HIV infected patients selected from an Indonesian prospective cohort study. PLoS ONE. 2013;8(Suppl 11):e79904.
22. Gomes AC, Gomes MS. Hematopoietic niches, erythropoiesis and anemia of chronic infection. Exp Hematol. 2016;44(Suppl 2):85-91.

23. Semba RD, Shah N, Klein RS, Mayer KH, Schuman P, Gardner LI, et al, Highly active antiretroviral therapy associated with improved anemia among HIV-infected women. AIDS Patient Care STDS. 2001;15:473-80

24. Moore RD, Forney D. Anemia in HIV-infected patients receiving highly active antiretroviral therapy. J Acquir Immune Defic Syndr. 2002;29:54-7.

25. Lipshultz HM, Hileman CO, Ahuja S, Funderburg NT, McComsey GA. Anemia is associated with monocyte activation in HIV-infected adults on antiretroviral therapy. Antivir Ther. 2015;20(Suppl 5):521-7.

26. Torti C, Raffetti E, Donato F, Castelli F, Maggiolo F, Angarano G, et al. Cohort profile: Standardized Management of Antiretroviral Therapy Cohort (MASTER Cohort). Int J Epidemiol. 2015. https://doi.org/10.1093/ ije/dyv192.

27. McLean E, Cogswell M, Egli I, Wojdyla D, de Benoist B. Worldwide prevalence of anemia, WHO Vitamin and Mineral Nutrition Information System, 1993-2005. Public Health Nutr. 2009;12(Suppl 4):444-54.

28. Rosado-Sánchez I, Jarrín I, Pozo-Balado MM, de Pablo-Bernal RS, HerreroFernández I, Alvarez-Ríos Al, et al. Higher levels of IL-6, CD4 turnover and Treg frequency are already present before CART in HIV-infected subjects with later low CD4 recovery. Antiviral Res. 2017;142:76-82.

29. Gianella S, Letendre S. Cytomegalovirus and HIV: a dangerous Pas de Deux. J Infect Dis. 2016;214(Suppl 2):S67-74.

30. Griesbeck M, Valantin MA, Lacombe K, Samri-Hassimi A, Bottero J, Blanc C, et al. HCV drives increased type I IFN-associated impairments associated to fibrosis severity in ART-treated HIV-1-HCV coinfected individuals. AIDS. 2017. https://doi.org/10.1097/QAD.00000000000001455.

31. Papasavvas E, Azzoni L, Yin X, Liu Q, Joseph J, Mackiewicz A, et al. HCV viremia associates with NK cell activation and dysfunction in antiretroviral therapy-treated HIV/HCV co-infected subjects. J Viral Hepat. 2017. https:// doi.org/10.1111/jvh.12714.

32. Lichtner M, Cicconi P, Vita S, Cozzi-Lepri A, Galli M, Lo Caputo S, et al. Cytomegalovirus coinfection is associated with an increased risk of severe non-AIDS-defining events in a large cohort of HIV-infected patients. J Infect Dis. 2015;211(Suppl 2):178-86.

33. Mena A, Meijide H, Rodríguez-Osorio I, Castro A, Poveda E. Liver-related mortality and hospitalizations attributable to chronic hepatitis $C$ virus coinfection in persons living with HIV. HIV Med. 2017. https://doi. org/10.1111/hiv.12502.

34. Hileman CO, Funderburg NT. Inflammation, immune activation, and antiretroviral therapy in HIV. Curr HIV/AIDS Rep. 2017;14(Suppl 3):93-100.

35. Balagopal A, Gupte N, Shivakoti R, Cox AL, Yang WT, Berendes S, et al. Continued elevation of interleukin-18 and interferon- $\gamma$ after initiation of antiretroviral therapy and clinical failure in a diverse multicountry human immunodeficiency virus cohort. Open Forum Infect Dis. 2016;3(Suppl 3):ofw118.

36. Pananghat AM, Aggarwal H, Prakash SS, Makhdoomi MA, Singh R, Lodha $\mathrm{R}$, et al. IL-8 alterations in HIV-1 infected children with disease progression. Medicine (Baltimore). 2016;95(Suppl 21):e3734.

37. Deeks SG, Tracy R, Douek DC. Systemic effects of inflammation on health during chronic HIV infection. Immunity. 2013;39(Suppl 4):633-45.

38. Kelesidis T, Jackson N, McComsey GA, Wang X, Elashoff D, Dube MP, et al. Oxidized lipoproteins are associated with markers of inflammation and immune activation in HIV-1 infection. AIDS. 2016;30(Suppl 17):2625-33.

39. Mastroianni CM, Lichtner M, Mascia C, Zuccala P, Vullo V. Molecular mechanisms of liver fibrosis in HIV/HCV coinfection. Int J Mol Sci. 2014;15:9184-208.

40. Shmagel KV, Saidakova EV, Shmagel NG, Korolevskaya LB, Chereshnev VA, Robinson J, et al. Systemic inflammation and liver damage in HIV/hepatitis C virus coinfection. HIV Med. 2016;17(Suppl 8):581-9.

41. Huang CF, Huang Cl, Yeh ML, Hou C, Hou NJ, Hsieh MY, et al. Disease severity and erythropoiesis in chronic hepatitis C. J Gastroenterol Hepatol. 2017;32(Suppl 4):864-9.

42. Balasubramanian A, Ganju RK, Groopman JE. Hepatitis C virus and HIV envelope proteins collaboratively mediate interleukin-8 secretion through activation of p38 MAP kinase and SHP2 in hepatocytes. J Biol Chem. 2003;278(Suppl 37):35755-66.

43. Zimmermann HW, Seidler S, Gassler N, Nattermann J, Luedde T, Trautwein C, et al. Interleukin-8 is activated in patients with chronic liver diseases and associated with hepatic macrophage accumulation in human liver fibrosis. PLoS ONE. 2011;6(Suppl 6):e21381. 
44. Veenhuis RT, Astemborski J, Chattergoon MA, Greenwood P, Jarosinski M, Moore RD, et al. Systemic elevation of proinflammatory interleukin 18 in HIV/HCV coinfection versus HIV or HCV monoinfection. Clin Infect Dis. 2017;64:589-96.

45. Macías J, Berenguer J, Japón MA, Girón JA, Rivero A, López-Cortés LF, et al. Fast fibrosis progression between repeated liver biopsies in patients coinfected with human immunodeficiency virus/hepatitis C virus. Hepatology. 2009;50(Suppl 4):1056-63.

46. Fujita N, Sugimoto R, Takeo M, Urawa N, Mifuji R, Tanaka H, et al. Hepcidin expression in the liver: relatively low level in patients with chronic hepatitis C. Mol Med. 2007;13(Suppl 1-2):97-104
47. Girelli D, Pasino M, Goodnough JB, Nemeth E, Guido M, Castagna A, et al. Reduced serum hepcidin levels in patients with chronic hepatitis $C$. J Hepatol. 2009;51(Suppl 5):845-52.

48. Zou DM, Sun WL. Relationship between hepatitis $C$ virus infection and iron overload. Chin Med J (Engl). 2017;130(Suppl 7):866-71.

49. Negash AA, Ramos HJ, Crochet N, Lau DT, Doehle B, Papic N, et al. IL-1 beta production through the NLRP3 inflammasome by hepatic macrophages links hepatitis $C$ virus infection with liver inflammation and disease. PLoS Pathog. 2013;9:e1003330

\section{Submit your next manuscript to BioMed Central and we will help you at every step:}

- We accept pre-submission inquiries

- Our selector tool helps you to find the most relevant journal

- We provide round the clock customer support

- Convenient online submission

- Thorough peer review

- Inclusion in PubMed and all major indexing services

- Maximum visibility for your research

Submit your manuscript at www.biomedcentral com/submit 